\title{
我国古代铸范、红烧土中的植物 硅酸体研究及其意义*
}

\author{
王永吉 吕厚远 吕海滨 \\ （国家海洋局第一海洋研究所，青岀 266003）

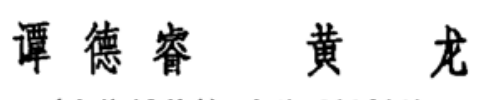 \\ (上海博物馆, 上海 200232)
}

\section{关业词铸范、红烧土、植物硅酸体}

植物硅酸体具有较强的耐热性以, 在经过高温焙烧的古代铸范、红烧土及土器中可以大量 保存下来. 对于这类难以保存花粉及其它化石遗体的古代遗物中的植物硅酸体研究, 可以了 解古代人类的生活环境、燃料、铸造工艺等许多古文化、古环境信息 ${ }^{[2]}$.

本文介绍的 10 个考古样品, 都已焙烧固结, 比较坚硬. 焙烧温度估计在 $600^{\circ} \mathrm{C}$ 以上, 分别 是: 南京六朝五铢钱范(公元 420-589 年); 山西东周侯马陶范(公元前 256-770 年); 河北战 国燕下都 10 号无名陶、7 号剑范、4号带钩花纹范、 2 号锤范(公元前 221-475 年); 洛阳铁路中 学西周陶范 (公元前 11 世纪-771 年); 郑州南关外商代陶范(公元前 $11-16$ 世纪); 河南新郑 仓城东周铸铁聥址红烧土; 山东充州王因大汶口文化考古遗址红烧土 ${ }^{12}$. 另外, 选取我国 10 个 不同类型的土壤样品及山西侯马、洛阳铁路中学、郑州南关外 3 个考古遗址原生土壤样品做植 物硅酸体对比性研究.

考古样品经破碎后取 $20 \mathrm{~g}$, 土壤样品取 $15 \mathrm{~g}$, 按照文献 [2]所介绍的方法进行分析处理制片, 在普通光学显微镜下进行鉴定. 除燕下都 7 号剑范中植物硅酸体军见外, 都发现了丰富的各 种类型植物硅酸体.

\section{一、植物硅酸体基础研究}

至今, 植物硅酸体分类是基于对禾本科、木本植物及其它草本植物的部分研究成果提出 的. 其中, 由于禾本科植物硅酸体含量丰富, 分类特征明显, 也较为系统. 自 1936 年 Prat 提 出简单的以形态为主的分类以来 ${ }^{[3]}$, 许多人在此基础上试图进行更完善的分类 ${ }^{[4,5]}$. 从恢复古 植被、古环境的角度看, 植物硅酸体分类应与植物分类有直接联系, 尽管这种完全相关的联 系是困难的, 在这方面近藤的分类较为合适 ${ }^{[3]}$. 参照近藤的分类, 结合我们已经研究的 150 余种现代禾本科植物硅酸体样品, 暂作以下分类: (1) 亚铃型, 相当于近藤 II 类(下同), 主 要起源于乘亚科; (2) 扇型、方型、长方型, 相当于IX 类, 是发育于机动细胞中的大型硅酸体,

本文1991年1月11日收到. 1991 年 6 月 20 日收到售改稆.

* 国家自然科学基金资助项目.

1) 山东公州王因红烧土样品由中国科学院植物研究所孔昭碾先生提供. 
在早熱禾亚科中极不发育, 常见于禾本科的另外 5 个亚科; (3)帽型、短齿型、长齿型, 相当于 IV 类,只见于早熟禾亚科; (4) 鞍型,相当于 IV 类,主要起源于画眉草亚科;(5)竹节型, 相当 于 III 类,主要起源于竹亚科;(6)平滑棒型、刺边棒型,相当于 VII 类,在各亚科中都有发现, 其它还有尖型、梯型及非禾本科植物起源的类型, 如团粒型、坡纹型等. 为了研究古代铸造工 艺中是否人工加人稻壳之类的植物质,特对现代稻壳(白聋糖灰、黑若糖灰)中的硅酸体形态进 行了分析观察, 稻壳中硅酸体含量极高, 可达干样重量的 $40 \%$ 左右, 形态特征明显 (图 1). 稻 売中的表皮细胞几乎全部被硅化,其硅酸体形态是一种特殊的表皮细胞被硅化的聚合体,聚合 体呈叠瓦状排列, 每排边缘有大型的刺状突起, 根据本文的特殊目的, 我们在图 3 中把它单独 区分出来。

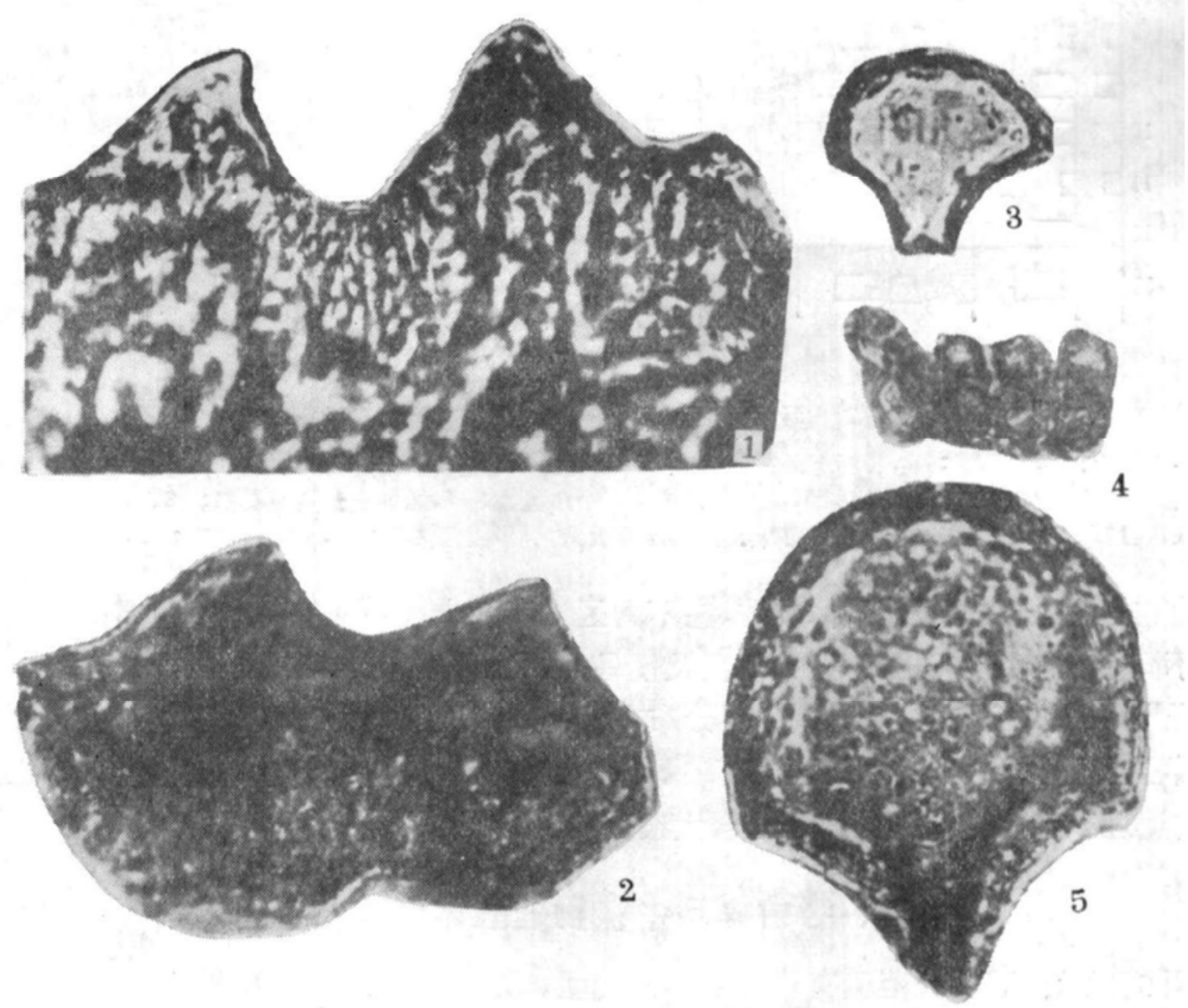

图 1 考古样品及现代榴壳中的植物硅酸体照片

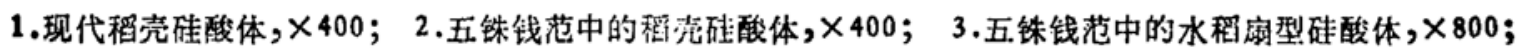

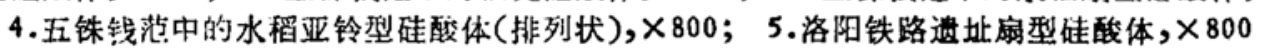

禾本科是广布于全球的有花植物中的第 5 大科, 现一般分为 6 个亚科, 各亚科都有自己最 适宜的生态环境. 画眉草亚科 (Eragrostoideae) 主要分布在南北回归线内少雨或不规则降雨 的热带干旱地区; 早熟禾亚科 (Festucoideae) 主要分布在南北纬 $30-55^{\circ}$ 的温寒地区以及夏 季凉爽的高海拔山地; 乘亚科 (Panicoideae) 沿赤道热带发展, 以南北纬 $30^{\circ}$ 以内降雨季节长 的地区最为丰富; 芦竹亚科 (Arundinoideae) 种属极少, 是一个特化类群, 适应性较强, 是最 适宜潮湿环境的高大草类; 竹亚科 (Bambusoideae) 集中分布在热带多雨温湿地区; 稻亚科 (Oryzoideae) 对水热条件都有较高的要求. 当然各亚科都有积极向不宜环境扩展获得 酎 (适应性)的能力, 以种子休眠、冬季落叶枯死、一年生比例增加等方式获得生存. 


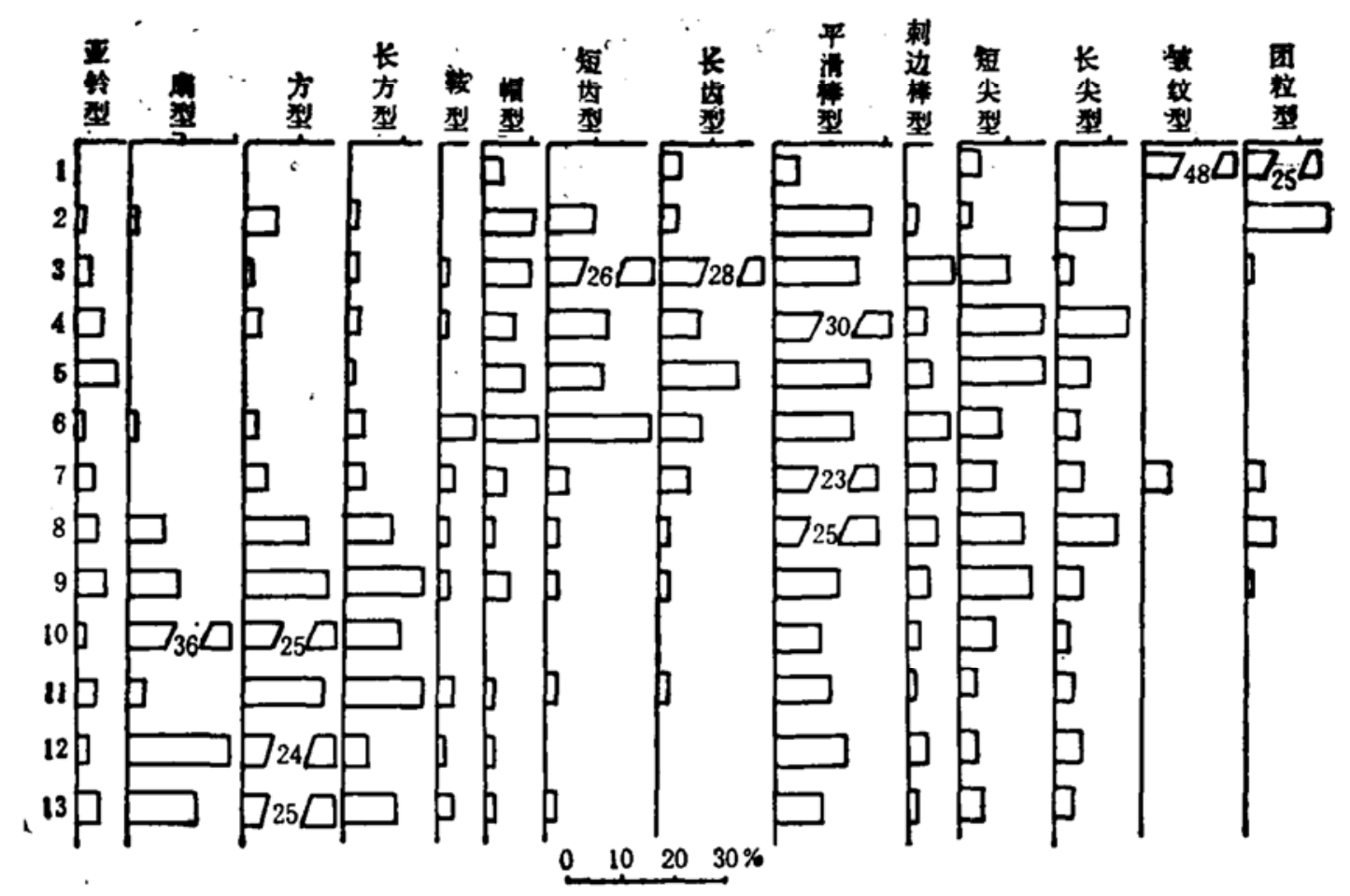

图 2 我国不同土㙥类型中植物硅酸体分布

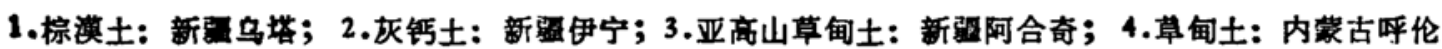

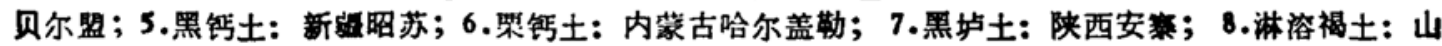

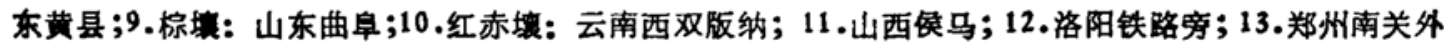

具有植物分类标志的硅酸体类型,在不同区域不同土壤类型中的含量也有很大差別,图 2 是我国不同土壤中植物硅酸体分布情况及侯马、洛阳、郑州三个考古遗址原生土中植物硅酸体 组合情况 ${ }^{2}$. 帽型、长齿型、短齿型主要分布在寒冷地区. 扇型、方型、长方型主要分布在温暖 地区. 棒型、尖型在相对干冷地区含量较多. 铍纹型、团粒型主要分布在极端千旱寒冷地区, 3 个考古遗址原生土中植物硅酸体组合大致反映了温暖的气候环境.

\section{二、考古样品中植物硅酸体组合特征}

如图 3 所示: 五铢钱范见有竹节型, 亚铃型, 还有大量禾本科机动 细胞发 育 的 扇型 $(7.2 \%)$ 、方型 $(6.7 \%)$ 、长方型 $(9.6 \%)$ 、鞍型 $(3 \%)$ 、棒型 $(27 \%)$, 而生长在北方温寒地区的早熟 禾亚科的长齿型、帽型没有发现, 反映了相对温暖的气候环境. 样品中发现大量水稻稻壳中的 特殊类型的硅酸体 $(24.5 \%)$, 发现少量水稻茎叶中发育的扇型、亚铃型硅酸体(图 1).据现代土 壤分析结果,稻壳硅酸体含量极少, 五铢钱范中稻壳硅酸体如此富集. 说明古人在铸造工艺 中加人了相当数量的稻壳(或稻壳灰). 侯马陶范中见有: 反映寒冷的早熟禾亚科的长齿型 (59\%)、短齿型 $(9.5 \%) 、$ 、帽型 $(9.5 \%)$ 硅酸体占绝对优势，其它类型少见，见一粒云杉花粉和较

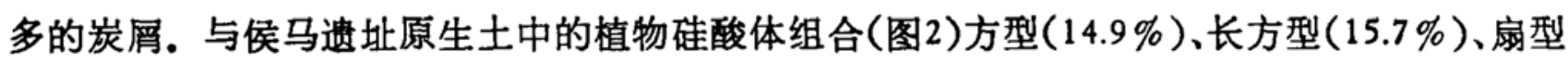
$(4.7 \%) 、$ 帽型 $(1.5 \%)$ 、长齿型、短齿型几乎为零相比有极大的差别. 在现代亚高山草甸土中, 长齿型达到最高 $(28 \%)$, 但仍远低于陶范中的含量, 推测古人在铸造工艺中加人了草物质或 草木灰, 草的来源是早熟禾亚科.

1）土境样品由中国科学院南京土㙋研究所顾国安先生提供. 


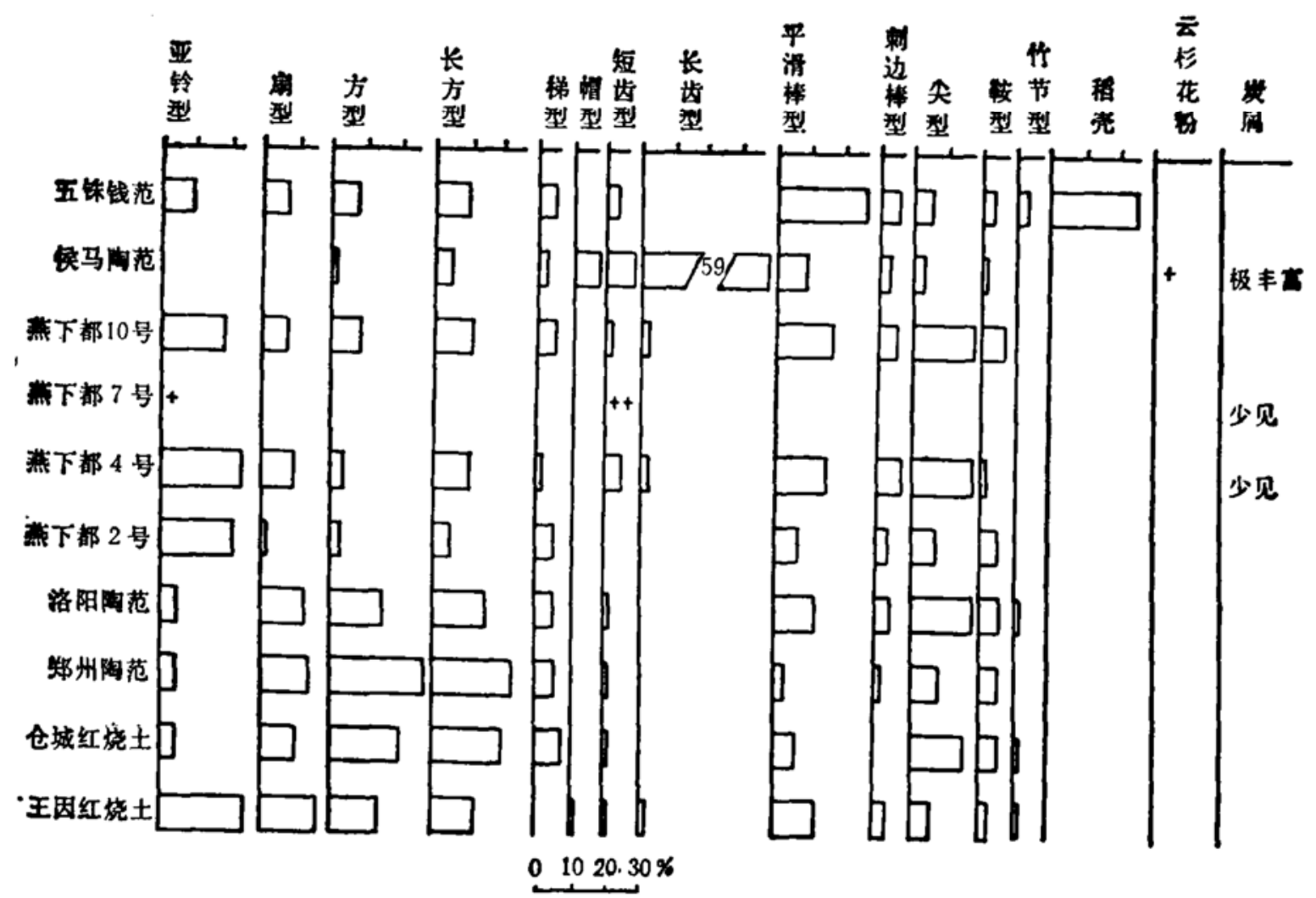

图 3 考古样品中植物硅酸体组合图式

燕下都考古样品中, 除 7 号剑范硅酸体罕见外, 10 号、4 号、2 号样品中硅酸体组合比较相 似, 亚铃型多在 $20 \%$ 以上, 尖型、棒型都在 10 - 20\% 左右, 齿型、帽型少见, 反映了温暖半湿润 的气候环境. 7号剑范之所以硅酸体罕见, 或许是铸造工艺中焙烧温度过高, 硅酸体熔化所致.

河南洛阳、郑州、新郑三个考古样品及洛阳、郑州二个考古遗址原生土中植物硅酸体组合 非常一致, 以扇型、方型、长方型为主, 尖型、棒型、鞍型有一定的含量,齿型、帽型少见, 反映了 相对温暖的植被类型.

山东王因红烧土中, 反映温䐘、湿润的亚铃型、扇型、方型、长方型占绝对优势. 王因遗址 形成于大汶口文化期 ( ${ }^{14} \mathrm{C}$ 年代: $5950 \pm 120 \mathrm{aB} . P ., 5225 \pm 130 \mathrm{aB} . P$. $)^{[6]}$, 遗址中有丰富的扬子 鲐 (Alligator sinensis Fauval) 及现在生长于亚热带辩鳃类遗䯚及水荻、风尾荻、海金沙等亚 热带厥类孢子, 说明当时气候温暖、湖沼发育。

把植物硅酸体应用于考古学的历史, 在国外不足 20 年, 80 年代有了更长足的发展. 考古 学是植物硅酸体应用最广泛的领域之一. 我国自1989年以来对于植物硅酸体的基础性研究及 应用做了一些探索性的研究工作 ${ }^{[7-9]}$. 预计在我国的考古学工作中,也会有广阔的应用前鲸。

[1] 渡边直經,考古学研究, 20(1973),65-73;21(1974),55-62.

[2] 近藤鍊三、佐濑 隆,第四紀研究,25(1986),1: 31-63.

[3] Prat, H., Ann. Sci. Nat. Bot. Biol. Ver., 18(1936), 165-258.

[4] Twiss, P.C., Suess, E. and Smith, R.M., Soil Sci. Soc. Amer. Proc., 33(1969), 109-115.

[5] 近藤镧三、佐濑 隆、相马 靖, 土肥要旨集,20(1983), 143 .

[6] 孔昭屒、杜乃欧, 海洋地质与第四纪地质, 10(1990),1: 99-102.

[7] 王永吉、吕厚远,黄潮海海洋, 7(1989),1: 66-68.

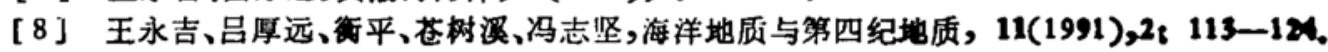

[9]吕厚远、王永吉,科学通报,34(1989),19: 1485-1488。 